\title{
EDUCAÇÃO PERMANENTE EM SAÚDE: REPRODUÇÃO OU CONTRA- HEGEMONIA?
}

\author{
PERMANENT EDUCATION IN HEALTH: REPRODUCTION OR COUNTER-HEGEMONY?
}

\begin{abstract}
Catharina Matos Leite ${ }^{1}$ iD (0000-0002-8131-4831), Isabela Cardoso de Matos Pinto ${ }^{1}$ (DD (0000-0002-1636-2909), Terezinha de Lisieux Quesado Fagundes ${ }^{1}$ iD (0000-0002-7033-2970)
\end{abstract}

\footnotetext{
${ }^{1}$ Universidade Federal da Bahia, Instituto de Saúde Coletiva, Salvador, Bahia, Brasil. <clms@ufba.br>
}

Resumo O objetivo do artigo foi refletir sobre as bases conceituais da educação permanente em saúde à luz dos conceitos de reprodução, de Bourdieu, e contra-hegemonia, de Gramsci. Analisa criticamente suas interfaces com a política, a gestão e a organização dos serviços de saúde, bem como os processos contra-hegemônicos na criação de espaços para promoção de transformações nas práticas de saúde. Busca também levantar um conjunto de hipóteses que possibilitem estudos sobre educação permanente em saúde, seus desafios e potencialidades no âmbito da implantação do Sistema Único de Saúde. Palavras-chave educação permanente em saúde; reprodução; contra-hegemonia; transformação de práticas de saúde.
Abstract This article aimed to reflect on the conceptual basis of permanent education in health, in the light of the concepts of reproduction, de Bourdieu, and counter-hegemony, of Gramsci. It critically analyzes the interfaces of permanent education in health with the policy, management and organization of health services, as well as the counter-hegemonic processes, in the creation of spaces to promote transformations in health practices. It also seeks to raise a set of hypotheses that enable studies on permanent education in health, its challenges and potentialities within the scope of Brazilian Unified Health System implementation.

Keywords permanent education in health; reproduction; counter-hegemony; transformation of health practices. 


\section{Introdução}

A preocupação com a qualificação dos profissionais de saúde não é recente no Brasil (Garcia, 1972). Desde os primeiros anos do século XX, experiências como a da Fundação Oswaldo Cruz contemplavam a formação de quadros em apoio à saúde pública brasileira. Na década de 1970, a formação dos trabalhadores passou a compor a agenda das organizações de saúde, em que o debate sobre as estratégias educacionais visava potencializar o desempenho das práticas, uma vez que os perfis dos trabalhadores nem sempre eram compatíveis com as necessidades dos serviços de saúde. Consequentemente, a formação para qualificar o processo de trabalho foi considerada um importante investimento para o desenvolvimento tanto dos trabalhadores quanto do sistema de saúde (Nunes, Fagundes e Soares, 2015).

Por um lado, essa problemática exigia respostas das instituições estatais formadoras, que se configuraram ao longo do tempo em um conjunto de iniciativas desdobradas em vários programas e políticas para atender a essa finalidade, a exemplo do Projeto Larga Escala, do Projeto de Profissionalização dos Trabalhadores da Área de Enfermagem (Profae) e do Programa de Incentivos às Mudanças Curriculares das Escolas Médicas (Promed), entre outros, elaborados pelo governo federal e executados pelos estados brasileiros (Dias, Lima e Teixeira, 2013). Por outro lado, no bojo das mudanças políticas, econômicas e sociais pós-democratização do país, o movimento da Reforma Sanitária Brasileira (RSB) e a criação do Sistema Único de Saúde (SUS) problematizavam as práticas de saúde desenvolvidas nos seus serviços, conformadas historicamente pelo modelo médico hegemônico (Brasil, 1988).

Entre os esforços recentes de implantação de programas e políticas de formação em saúde encontra-se a Política de Educação Permanente em Saúde (EPS), que se articula ao trabalho e à gestão em saúde, cuja reflexão teórica, conceitual e política pretende contribuir para a reorganização das práticas de saúde no âmbito dos serviços (Ribeiro e Motta, 1996).

Vale ressaltar que, historicamente, esse processo de implantação da EPS foi complexo e permeado de numerosos entraves e obstáculos enraizados na pedagogia hegemônica de matriz flexneriana das instituições de ensino superior (IESs), voltadas para a formação graduada do pessoal da saúde. Essa perspectiva educacional predominante no âmbito da formação médica e dos demais profissionais da saúde está ancorada na clínica, visa à acumulação de capital no complexo médico-industrial, é estimulada pelas facilidades geradas com a incorporação de tecnologias materiais e apoia-se na relativa efetividade simbólica dessa prática em saúde (Paim, 1994). 
A busca na literatura revelou um número considerável de estudos sobre a EPS que tanto abordam as experiências do processo formativo (Fernandes, 2012; Stahlschmidt, 2012; Barbosa, Ferreira e Barbosa, 2012) como descrevem a concepção de educação presente no processo educativo (Silva e Peduzzi, 2011; Silva et al., 2017).

Identificam-se ainda investigações que tratam da concepção dos atores acerca dos processos formativos (Amador et al., 2011), bem como da análise dos fatores que interferem nos processos educativos (Jesus et al., 2011). Também os processos de implementação da EPS constituem-se objeto de investigação da educação permanente (Souza e Costa, 2016; Silva et al., 2017). Os resultados desses estudos apresentam contribuições significativas para os serviços de saúde, apontam questões do trabalho refletidas no cotidiano, assim como as condições reais em que os processos educativos acontecem, e evidenciam a concepção de educação dominante nos processos educativos, entre outros aspectos.

Entretanto, a questão que se apresenta aqui é a reflexão sobre o papel da EPS e os espaços possíveis de sua atuação na formação do trabalhador de saúde. Assim, esse problema é aqui discutido de forma aproximativa, tendo como foco as várias interfaces da EPS com a política, a gestão, a organização e o poder em saúde, assim como o desenvolvimento concomitante de processos contra-hegemônicos, promotores de transformações nas práticas sociais de saúde nos espaços onde elas se reproduzem.

Considera-se também que o desenvolvimento desses processos educativos é orientado pelas diretrizes políticas, pelos princípios e concepções teóricas que iluminam as políticas de saúde em geral. Tais processos educativos defrontam-se com complexos desafios na prática, em face das mudanças no mundo do trabalho em geral, em particular no lócus onde eles se desenvolvem. Demandam investimentos em estratégias educacionais para seu enfrentamento e objetivam reorientar, ajustar, inovar ou mesmo transformar as práticas de saúde. Todavia, essas mudanças possibilitam uma complexa convivência, muitas vezes conflitante e desarticulada de vários modelos educacionais para a formação do profissional da saúde, permeados por distintos interesses e jogos de poder, no âmbito dos serviços de saúde. Daí a necessidade de tratar e analisar a implementação desses processos educativos no âmbito das relações entre a organização, a gestão, a política e o poder em saúde (Paim, 1994), já que eles se encontram na interface entre os processos políticos de ordem mais geral e os especificamente vinculados aos campos da saúde e da educação.

Este artigo objetiva recuperar as bases conceituais da educação permanente em saúde, dialogando com os conceitos de reprodução (Bourdieu, 1992) e contra-hegemonia (Gramsci, 1978) e as possibilidades da EPS de produzir mudanças e transformações no status quo das organizações e, por sua vez, das práticas de saúde. 


\section{O debate conceitual sobre a educação permanente em saúde}

A preparação dos profissionais de saúde para a atuação no SUS pressupõe o encontro de duas categorias fundamentais: formação e trabalho, o que foi difundido nos primeiros anos de implantação do SUS com a denominação de educação continuada em saúde, mais recentemente conhecida como educação permanente em saúde (Paim e Nunes, 1992; Nunes, 1993).

Historicamente, o papel da Organização Pan-Americana da Saúde (Opas) foi importante, visto que, já em 1978, contribuiu para a formação dos profissionais de saúde, ao elaborar diretrizes para a formulação do Plano de Educação Continuada para as equipes nas instituições de saúde (Fagundes e Pinto, 2012). Em 1979, esse arcabouço conceitual da educação continuada começou a dialogar com os princípios fundamentais da educação de adultos e incorporou elementos teóricos conceituais-chaves, tais como aprendizagem significativa e importância da experiência dos sujeitos, dentre outros (Davini, 1995).

A expressão 'educação permanente' foi cunhada pela primeira vez na Europa em meados dos anos 1960, bem como utilizada em artigos publicados pela Comissão Europeia e pela Organização das Nações Unidas para a Educação, a Ciência e a Cultura (Unesco) (Ryan, 1999). Na década seguinte, Furter (1974, p. 79) definiu educação permanente como:

Um processo ininterrupto de aprofundamento tanto da experiência pessoal como da vida coletiva que se traduz pela dimensão educativa que cada ato, cada gesto, cada função assumirá, qualquer que seja a situação em que encontramos qualquer que seja a etapa de existência que estejamos vivendo.

Na América Latina e no Brasil, o uso do termo relaciona-se com a influência da Opas, que passa a disseminar uma 'nova' concepção de educação continuada, chamada educação permanente. Segundo Ricas (1994, p. 9), citado por Motta, Buss e Nunes (2001), o termo 'continuada' teria enfoque mais técnico e "englobaria as atividades de ensino após o curso de graduação, com finalidades mais restritas de atualização, aquisição de novas informações e/ou atividades de duração definida". Já o termo 'permanente', segundo o mesmo autor, envolveria um enfoque integrado técnico-organizacional e político e

Teria como referência uma estratégia de reestruturação e desenvolvimento dos serviços, a partir de uma análise dos determinantes sociais e econômicos, mas sobretudo de transformação de valores e conceitos dos profissionais. Propõe transformar o profissional em sujeito, colocando-o no centro do processo de ensino/ aprendizagem (Ricas, 1994, p. 9). 
As ações de educação continuada, portanto, caracterizam-se pela formação pontual com o objetivo de responder às lacunas na atuação técnica dos profissionais. Todavia, os esforços de vincular a formação e o processo ensino-aprendizagem às situações de trabalho seriam superados pela educação permanente, que contemplaria a integração de aspectos técnicos com aspectos políticos relativos à responsabilização compartilhada com o processo educativo entre profissionais e educadores.

Davini (1995) ressalta que os programas de educação permanente se baseiam na perspectiva 'integral' de análise do contexto e das práticas, visando à melhoria do processo de trabalho da equipe e à qualidade da atenção e transformação do serviço de saúde, daí que 'a educação é integrada aos processos de trabalho nos serviços de saúde'. Para tanto, distintos grupos sociais que assumem responsabilidades na transformação técnica, organizacional e política das instituições buscam diferentes fontes de informação para serem atualizados, bem como a formação permanente para o trabalho, em organizações cada vez mais complexas.

Em suma, a transformação do trabalho é o objetivo central da educação permanente na saúde, e esta visa à reorganização e melhoria da gestão e da qualidade dos serviços, ao possibilitar cuidados e acesso aos serviços de saúde com equidade. Vale ressaltar que o trabalho constitui o homem na sua especificidade; interfere em todas as dimensões da vida humana, extrapolando a atividade laboral. Aparece então como uma atividade que responde à produção dos elementos da vida biológica, mas também ao conjunto de necessidades do homem: intelectuais, culturais, simbólicas, lúdicas, afetivas, entre outras, assumindo especificidades no tempo e no espaço (Frigotto, 2008). Como causa e consequência, o trabalho é revalorizado e passa a ser o ponto central e espaço priorizado de formação, capacitação e educação permanente da força de trabalho na saúde. Essa perspectiva demanda mudanças na gestão e organização do trabalho e nos processos de ensino-aprendizagem até então vigentes em saúde, exigindo alternativas metodológicas criativas coerentes com e para esse mundo do trabalho (Saviani, 1994).

Na perspectiva da EPS, as iniciativas das metodologias ativas são especialmente estimuladas, inspiradas pela pedagogia do oprimido (Freire, 1971; $1978 ; 2001 ; 2006)$, de sorte a atender a formação das novas competências e habilidades, objetivando a aprendizagem significativa permanente (Ausubel, 2000; Delors, 1996) nos desafios para aprender a ser, a fazer, a viver junto, a conhecer. Busca-se também assegurar a formação do trabalhador de saúde pautada na integralidade da atenção, qualidade e humanização do modelo de atenção vigente na política de EPS no país (Arroyo, 2002; Vasconcelos, 1997).

Nesse sentido, o trabalhador da saúde é o sujeito que constrói e organiza seu próprio conhecimento; sua aprendizagem se dá no processo de trabalho, em interação com a equipe de trabalho da saúde. E o educador desempenha 
o papel de mediador desse processo, visando à superação das fragmentações e departamentalizações do saber, visto que, segundo Mitre e colaboradores (2008, p. 2.136),

$\mathrm{O}$ ato de aprender deve ser, portanto, um processo reconstrutivo, que permita o estabelecimento de diferentes tipos de relações entre fatos e objetos, desencadeando ressignificações/reconstruções e contribuindo para a sua utilização em diferentes situações.

A pedagogia orientadora dos processos de educação permanente corresponde à 'pedagogia do trabalho' que estaria em direção oposta ao que se diz ser a 'educação para o trabalho', em que os indivíduos se profissionalizariam para exercerem uma determinada ocupação/profissão ou se qualificarem para ela, num determinado mercado de oferta e demanda de recursos humanos, a chamada mão de obra. Nesse contexto, segundo a pedagogia do trabalho (Marx, 1867), o ser humano, ao trabalhar, estaria se formando e dando sentido ao seu mundo, ao mundo do trabalho, indissociavelmente imbricado à sua existência e à sociedade em que vive.

No entanto, esse mundo do trabalho historicamente contextualizado no âmbito do Sistema Único de Saúde é complexo, político, social, econômico; é permeado pela ética e está em construção, o que o torna pleno de contradições e conflitos, passível de ser transformado pelos seus sujeitos centrais de atuação, ou seja, pela ação dos trabalhadores da saúde. Daí o trabalho ser educativo e considerado dialeticamente na sua dupla dimensão: a primeira refere-se à possibilidade de o trabalho atuar na criação e na reprodução da vida humana; a segunda, à possibilidade simultânea de alienar e conscientizar e dar sentido à vida do ser humano (Marx, 1867).

Ao refletir sobre o trabalho como princípio educativo, Frigotto, Ciavatta e Ramos $(2005$, p. 2) ressaltam que:

O trabalho como princípio educativo vincula-se, então, à própria forma de ser dos seres humanos. Somos parte da natureza e dependemos dela para reproduzir a nossa vida. E é pela ação vital do trabalho que os seres humanos transformam a natureza em meios de vida. Se essa é uma condição imperativa, socializar o princípio do trabalho como produtor de valores de uso, para manter e reproduzir a vida, é crucial e 'educativo'. Trata-se, como enfatiza Gramsci, de não socializar seres humanos como 'mamíferos de luxo'. É dentro desta perspectiva que Marx sinaliza a dimensão educativa do trabalho, mesmo quando o trabalho se dá sob a negatividade das relações de classe existentes no capitalismo. A própria forma de trabalho capitalista não é natural, mas produzida pelos seres humanos. A luta histórica é para superá-la. 
Esses mesmos autores sugerem que nessa relação de produção dos meios de vida pelo trabalho poder-se-ia transformar a natureza e a si mesmos, à medida que os seres humanos teriam a atividade prática e a cultura como ponto de partida do conhecimento e da conscientização. Essa conscientização seria adquirida por meio do trabalho ou pela ação do ser humano sobre a natureza (Frigotto, Ciavatta e Ramos, 2005).

Segundo Saviani (1989), o trabalho como princípio educativo determinaria o modo de ser da educação em seu conjunto, caracterizando-se por distintos modos de educar; apresenta exigências específicas aos processos educativos e, finalmente, determina a educação como uma modalidade diferenciada de trabalho: o trabalho pedagógico.

Nesse enfoque, a educação teria vários papeis políticos ao exercer suporte à visão de mundo hegemônica e contribuir para reproduzir os interesses do capital no mundo do trabalho, assim como da ideologia dominante em cada momento histórico. Porém, esses papéis não seriam exercidos de forma linear nem unidirecional. Os interesses e conflitos das relações sociais inscritas na sociedade de classes e do capital se enunciam no mundo do trabalho, por meio tanto das relações de produção como do processo produtivo, e contribuem para que ocorram mudanças específicas demandadas e provocadas pelas próprias modificações do trabalho. $\mathrm{O}$ que, no caso da saúde, envolve, por exemplo, a inclusão de novas tecnologias, de novas profissões e sujeitos do trabalho, do trabalho em equipe, e mudanças nos modelos de gestão, entre outras questões (Saviani, 1989).

Haveria, por conseguinte, espaços e possibilidades para que a educação da força de trabalho em saúde possa também, simultaneamente, ser veículo da visão de mundo contra-hegemônica e contribuir para mudanças no mundo do trabalho e na sociedade. Essa compreensão se vincula à proposta da educação permanente em saúde, como tentativa transformadora das práticas de saúde dos trabalhadores, por meio da desalienação dos sujeitos e do desenvolvimento de sua consciência crítica sobre a realidade social em que estão inseridos.

\section{Educação permanente em saúde, reprodução e contra-hegemonia}

A literatura sobre educação na saúde (Paim, 1994; Pinto et al., 2013), em especial a EPS, trata frequentemente da pedagogia adotada, das metodologias e estratégias pedagógicas, da concepção que orienta os processos educativos; pouco analisa os determinantes da educação permanente acerca das condições sob as quais ela se realiza - o que implicaria a compreensão do seu contexto político, histórico e social (Testa, 1997).

E a educação permanente em saúde nos dias atuais, na sociedade brasileira? O ponto de partida para seu entendimento poderia ser meio da análise do lócus onde se desenvolve a EPS; em segundo lugar, pela reflexão acerca dos propósitos de seus processos educativos. 
Ao lócus correspondem as organizações de saúde e instituições burocráticas caracterizadas por divisão do trabalho e poder (Grupo de Análise de Políticas de Inovação-Unicamp, 2002), conhecidas como hipercomplexas (Testa, 1997), que por sua vez dão suporte às ações dos sujeitos sociais e refletem a natureza do Estado e suas relações com a sociedade. Sofrem, portanto, determinações econômicas, políticas e sociais.

A configuração política em cada momento histórico define conceitos e a forma como os processos vão se desenvolver, bem como a perspectiva a ser adotada. O trabalho como princípio educativo pode estar relacionado à perspectiva do patrão - predominantemente a serviço da reprodução em detrimento da formação da consciência crítica (Bourdieu, 1992; Passeron, 2009). Entretanto, uma visão mais emancipadora consideraria esses processos como parte da luta hegemônica entre capital e trabalho (Frigotto, Ciavatta e Ramos, 2005). Daí que a educação permanente não seria tarefa inocente; situa-se no âmbito dos embates que se efetivam no conjunto das relações sociais. Essas relações sociais se expressam nas organizações de saúde que, por sua vez, refletem o conjunto das relações entre o Estado, a sociedade e suas características.

As práticas educativas também refletiriam predominantemente a ideologia dirigente, que por seu turno ancora-se na concepção de educação 'para' o trabalho, investindo na capacitação dos trabalhadores para o 'bom' desempenho das suas funções institucionais e não necessariamente propiciando a sua consciência crítica. Essa educação estaria favorecendo a manutenção do status quo nas organizações, por conseguinte a manutenção de grupos hegemônicos no poder (Freitag, 1986).

Arouca (2003) distingue o conceito de ideologia como sistema de ideias e representações que dominam o espírito do homem ou de um grupo social - do conceito de prática ideológica, atividade realizada no sentido de transformar uma ideologia dada em outra ideologia. Assim, no que concerne à prática ideológica, indaga-se se os formuladores dos processos educativos em EPS estariam interessados em transformar uma ideologia em outra, mudando, por conseguinte, as visões de mundo que circulam no mundo do trabalho em saúde.

A EPS, no âmbito das políticas de saúde contemporâneas, é em geral articulada aos processos de trabalho e, por conseguinte, às mudanças das práticas por meio do trabalho numa perspectiva teoricamente contra-hegemônica da saúde, advogada pelos princípios da Reforma Sanitária Brasileira. Todavia, na maioria das vezes, parece que as mudanças preconizadas para serem realizadas pela educação nas práticas de saúde resultariam em 'novas' práticas de caráter predominantemente técnico e limitado quanto às mudanças na direção intelectual e moral contra-hegemônicas no âmbito das organizações de saúde, na perspectiva de Gramsci (1989) e do estudo de Macciochi (1976).

Nota-se que as organizações e instituições são genuinamente contraditórias e dialéticas como espaços para o desenvolvimento de resistências e também de 
processos contra-hegemônicos (Gramsci, 1966). Porém, determinadas conjunturas podem favorecer e viabilizar mudanças, a depender das necessidades, das articulações e alianças das forças hegemônicas e contra-hegemônicas no tempo histórico. As disputas são também processos sociais, espaço de alternativas ou uma luta de tendências, em que o resultado relaciona-se com o resultado das lutas entre 'vontades coletivas' organizadas (Coutinho, 1981; 1998).

Assim, é possível pensar que os trabalhadores da saúde, como sujeitos sociais, poderiam promover mudanças nas práticas de saúde desenvolvidas nas instituições de saúde, potencializando o binômio instituinte-instituído, reforçando a tese de que a direção da educação permanente em saúde constituiria uma decisão política. Como decisão política, estaria alinhada aos propósitos de determinado governo - e segundo Testa (1992), esses propósitos poderiam ser de mudança, crescimento ou legitimação. Ou ainda responder ao binômio conservar mudando e mudando para conservar (Paim, 2008).

A conformação de consciência crítica viabilizada pelo trabalho desenvolveria uma práxis, já que conhecimento e práxis são inseparáveis, e esse conhecimento é ideologia; serve de base para construir uma visão de mundo ou de uma práxis política. O social e o político não são desvinculados do econômico, que corresponde à esfera mediadora entre a produção material e a esfera da vida humana, cujo resultado seria um novo processo civilizatório, construído de 'baixo para cima', articulado com a produção de conhecimentos e artefatos culturais (Coutinho, 1981;1998).

A cultura é, portanto, veículo para o desenvolvimento de consciência crítica do ser social que, por sua vez, constitui o sujeito coletivo (Testa, 2007). A cultura não seria aquisição de conhecimentos, mas aquela necessária para fazer a crítica à ordem das coisas. Assim, os sujeitos trabalhadores da saúde poderiam, a partir da cultura, tomar partido, posicionar-se ante a história, buscando mudanças e transformações individuais e coletivas. Essa cultura possibilitaria ultrapassar o caráter heterogêneo e imediato da vida cotidiana vista nas lutas econômicas corporativas, indo em direção a lutas mais duradouras, visando à construção de uma nova 'hegemonia' (Simionatto, 1998).

O propósito, então, da educação permanente em saúde estaria ligado à articulação de vontades coletivas, conformação de sujeito coletivo, o que possibilitaria viabilizar mudanças no mundo do trabalho concomitantemente à busca da construção de um cenário político institucional contra-hegemônico. Decerto, nessa abordagem, a prática educativa por meio da educação permanente em saúde pode parecer utopia, mas espera-se que possibilite o desenvolvimento de uma atitude crítica e consciente nos sujeitos no campo das ideias e da cultura, manifestando a capacidade de conquistar o consenso e formar uma base social em prol do desenvolvimento de uma práxis transformadora (Testa, 1997). 
A necessidade de uma práxis transformadora remete à questão da decisão em saúde, que segundo Testa (1997) aponta para o exercício da práxis política e a construção de outras práticas nas organizações de saúde, cuja constituição de aptidão crítica foge à crítica pela crítica e desenvolve o sujeito para a ação. Nesse caso, a ação teria como foco o trabalho e seus processos necessários, a educação e suas metodologias de ensino - aprendizagem e as mudanças contextuais.

Desse modo, os trabalhadores de saúde criticamente conscientes poderiam deixar sua passiva condição de subordinação e agentes reprodutores. Poderiam eles passar a produzir fatos e mudar situações (Matus, 1996). Nessa direção, conquistariam espaços e posições, sem perder de vista o objetivo final de transformação social, e se buscaria a constituição da práxis política que tenha como propósito 'uma reforma intelectual e moral', a fim de superar os interesses coorporativos de classe em prol da unicidade; do modo de pensar desagregado em detrimento de uma forma de pensar crítica e coerente (Gramsci, 1966).

O campo da saúde, ao ser permeado por interesses específicos de classe, por meio das disputas entre o público e o privado ou entre grupos específicos, demandaria a construção de uma nova civilitá (Simionatto, 1998). Nesse sentido, as mudanças seriam iniciadas no microcosmo das organizações, no âmbito da gestão por meio da EPS, com movimentos sucessivos de rompimento do instituído, possibilitando a inserção da criatividade e, por conseguinte, proporcionando maior autonomia aos sujeitos. Assim, a educação permanente em saúde parece possibilitar a criação das condições para que os sujeitos possam ser intelectuais e políticos, para agir e pensar, conceber e propor, analisar e 'prever', exaltando a dialética da unidade, do diverso, da totalidade.

Essa perspectiva emancipadora, por um lado, contrapõe-se aos limites apontados em relatos de experiência encontrados na literatura (Feuerwerker, Kalil e Baudy, 2000) sobre os investimentos em processos educativos por meio da EPS, tanto pedagógicos quanto financeiros; por outro, destaca que obstáculos estruturais imprimem sérias limitações dificultando as mudanças dos espaços de trabalho. A hipótese concorrente seria que esses processos, por se concretizarem em espaços que representam o Estado, estariam mais próximos da sua manutenção/conservação, bem como do binômio conservar mudando para conservar, servindo mais para a reprodução da força de trabalho e menos para a contribuição em sua mudança. Esses seriam movimentos simultâneos, articulados às propostas governamentais, e corresponderiam às intenções de governos em conjunturas específicas. Resta saber em que medida o uso da educação permanente em saúde não se configura apenas como um 'modismo', como mais um processo educativo com nomenclatura que sugere novidade, mas com a manutenção da velha roupagem no âmbito das organizações de saúde. 


\section{Considerações finais}

A formação dos trabalhadores da saúde faz parte da agenda governamental e se institucionalizou no âmbito das secretarias estaduais, por meio das escolas técnicas e das escolas de saúde pública. Os gestores do SUS têm procurado influenciar na redefinição do perfil dos profissionais, inserindo variadas iniciativas programáticas integrando educação, trabalho, gestão e organização dos serviços, de sorte a possibilitar mudanças na formação e nas práticas de saúde.

A educação permanente, nesse sentido, é considerada como uma possibilidade de provocação dessas mudanças. Entretanto, estudos sobre o papel da instituição escolar (Bourdieu, 1992) sugerem que a escola favoreceria muito mais a reprodução e a inculcação da visão de mundo hegemônica do que mudanças contra-hegemônicas (Freitag, 1986; Macciocchi, 1976).

Por sua vez, a educação permanente em saúde, como política, é complexa e contraditória, podendo desencadear simultaneamente processos hegemônicos e contra-hegemônicos, visto que a educação contribuiria para a formação dos trabalhadores, desenvolvendo sujeitos aderentes ao status quo mas também com aptidões críticas, que a depender das condições objetivas poderiam mudar esse status quo (Testa, 2007). A educação permanente, nessa perspectiva, poderia atuar como instrumento pedagógico transformador; e a organização de saúde como uma instituição, permeada por contradições, que estaria potencialmente aberta às mudanças e à conservação do setor saúde.

Diante do exposto, ficam a provocação e o convite para o aprofundamento das reflexões e investimento em novos estudos que possam responder às inquietações levantadas e aos desafios do trabalho e da educação na saúde. Sem dúvida, se faz necessário melhor conhecer, acompanhar e avaliar as iniciativas que ocorrem na educação no mundo do trabalho da saúde, particularmente no âmbito do SUS. Este, por ser visto também como uma escola, demanda especial atenção no que tange à concretização de seus princípios e fundamentos, tais como o do componente da participação, controle social e integralidade, entre outros, que têm caráter contra-hegemônico e parecem encontrar obstáculos para sua absorção como cultura do/no mundo do trabalho.

\section{Colaboradores}

Catharina Matos participou da concepção do artigo, escreveu parte do seu conteúdo e revisou todas as etapas até a revisão final. Isabela Cardoso de Matos Pinto e Terezinha de Lisieux Quesado Fagundes colaboraram na redação do artigo e parte da revisão. 


\section{Financiamento}

Este suplemento “Educação e Trabalho em Saúde: diálogos e experiências no Brasil e em Portugal” foi realizado com apoio da Coordenação de Aperfeiçoamento de Pessoal de Nível Superior (Capes) - Código de Financiamento 001; e do Departamento de Pesquisa em História das Ciências e da Saúde da Casa de Oswaldo Cruz (Depes/COC/Fiocruz, 6151000000). Todos os autores declaram que não há conflito de interesses.

\section{EDUCACIÓN PERMANENTE EN SALUD: ¿REPRODUCIÓN O CONTRAHEGEMONÍA?}

Resumen Ese artículo tiene como objetivo reflejar sobre las bases conceptuales de la educación permanente en salud, a la luz de los conceptos de reproducción de Bourdieu, y contrahegemonía, de Gramsci. Analiza críticamente las interfaces de la educación permanente en salud con la política, gestión y organización de los servicios de salud, así como los procesos contrahegemónicos, e la creación de espacios para promoción de transformaciones en las prácticas de salud. También busca plantear un conjunto de hipótesis que posibiliten estudios sobre educación permanente en salud, sus desafíos y potencialidades en el ámbito de la implantación del Sistema Único de Salud brasileño. Palabras clave educación permanente en salud, reproducción, contra hegemonía, transformación de prácticas de salud.

\section{Referências}

AMADOR, Daniela D. et al. Concepção dos enfermeiros acerca da capacitação no cuidado à criança com câncer. Texto \& Contexto Enfermagem, Florianópolis, v. 20, n. 1, p. 94-101, mar. 2011.

AROUCA, Sergio. O dilema preventivista: contribuições para a compreensão e crítica da medicina preventiva. São Paulo: Unesp; Rio de Janeiro: Fiocruz, 2003.

ARROYO, Miguel G. A atualidade da educação popular. Revista de Educação Pública, Cuiabá, v. 11, n. 19, p. 129-137, jan./jun. 2002.

AUSUBEL, David P. Retenção de conhecimentos: uma perspectiva cognitiva. Lisboa: Plátano Edições Técnicas, 2000.

BARBOSA, Vanessa B. A., FERREIRA, Maria L. S. M.; BARBOSA, Pedro M. K. Educação permanente em saúde: uma estratégia para a formação dos agentes comunitários de saúde. Revista Gaúcha de Enfermagem, Porto Alegre, v. 33, n. 1, p. 56-63, 2012.
BOURDIEU, Pierre. A reprodução. Rio de Janeiro: Francisco Alves, 1992.

BRASIL. Constituição da República Federativa do Brasil de 1988. Disponível em: <http:// www.planalto.gov.br/ccivil_03/constituicao/ ConstituicaoCompilado.htm > . Acesso em: 26 ago. 2019.

COUTINHO, Carlos N. Fontes do pensamento de Gramsci. Porto Alegre: L\&PM, 1981.

COUTINHO, Carlos N. Socialismo e democracia: a atualidade de Gramsci. In: AGGIO, Alberto (Org.). Gramsci: a vitalidade de um pensamento. São Paulo: UNESP, 1998, p.15-36. Disponível em: http://www.afoiceeomartelo. com.br/posfsa/Autores/Aggio, \%20Alberto/ Gramsci \% 20-\%20A\%20Vitalidade \% 20 de\%20um\%20pensamento.pdf. Acesso em: 13 set. 2019.

DELORS, Jacques. Educação: um tesouro a descobrir. Lisboa: Unesco/ASA, 1996. 
DIAS, Henrique S.; LIMA, Luciana D.; TEIXEIRA, Márcia. A trajetória da política nacional de reorientação da formação profissional em saúde no SUS. Ciência \& Saúde Coletiva, Rio de Janeiro, v. 18, n. 6, p. 1.613-1.624, 2013.

FAGUNDES, Terezinha L. Q.; PINTO, Isabela C. M. Caminhos da educação na saúde: notas para debate. Salvador: UNASUS, 2012. (Curso de Formação em Mediadores de Aprendizagem).

FERNANDES, Rosa M. C. Educação permanente nas situações de trabalho de assistentes sociais. Trabalho, Educação e Saúde, Rio de Janeiro, v. 10, n. 3, p. 481-505, 2012.

FEUERWERKER, Laura; KALIL, Maria E.; BAUDY, Rossana J. A construção de modelos inovadores de ensino-aprendizagem: as lições aprendidas pela Rede Unida. Divulgação em Saúde para Debate, Rio de Janeiro, v. 22, p. 49-62, dez. 2000.

FREIRE, Paulo. Ação cultural para a liberdade: extensão ou comunicação? Rio de Janeiro: Paz e Terra, 1971.

FREIRE, Paulo. Pedagogia do oprimido. Rio de Janeiro: Paz e Terra, 1978.

FREIRE, Paulo. Educação e mudança. Rio de Janeiro: Paz e Terra, 2001.

FREIRE, Paulo. Pedagogia da autonomia: saberes necessários à prática educativa. São Paulo: Paz e Terra, 2006.

FREITAG, Barbara. Escola, estado e sociedade. São Paulo: Moraes, 1986.

FRIGOTTO, Gaudêncio. Trabalho. In: PEREIRA, Isabel B. Dicionário de educação profissional. 3. ed. Rio de Janeiro: Fiocruz, 2008. p. 399-407.

FRIGOTTO, Gaudêncio; CIAVATTA, Maria; RAMOS, Marise. Política de educação profissional no Governo Lula: um percurso histórico controvertido. Educação \& Sociedade, Campinas, v. 26, n. 92, p. 1.087-1.113, 2005.
FURTER, Pierre. Educação permanente e desenvolvimento cultural. Petrópolis: Vozes, 1974.

GRUPO DE ANÁLISE DE POLÍTICAS DE INOVAÇÃO/UNIVERSIDADE ESTADUAL DE CAMPINAS (GAPI-UNICAMP). Metodologia de análise de politicas públicas. Campinas: Unicamp, 2002.

GARCIA, Juan C. La educación médica en la América Latina. Washington, D.C: OPS, 1972.

GRAMSCI, Antonio. A concepção dialética da história. 4. ed. Rio de Janeiro: Civilização Brasileira, 1966.

GRAMSCI, Antonio. Cadernos do cárcere. Rio de Janeiro: Civilização Brasileira, 1978. v. 2, 3 e 5.

GRAMSCI, Antonio. Os intelectuais e a organização da cultura. Rio de Janeiro: Civilização Brasileira, 1989.

JESUS, Maria C. P. et al. Educação permanente em enfermagem em um hospital universitário. Revista da Escola de Enfermagem da USP, São Paulo, v. 45, n. 5, p. 1.229-1.236, out. 2011.

MACCIOCCHI, Maria A. A favor de Gramsci. São Paulo: Paz e Terra, 1976.

MARX, Karl [1867]. The Grundrisse. In: TUCKER, Robert C. (ed.). The Marx-Engels: reader. New York: W.W. Norton \& Company, 1978.

MATUS, Carlos. Estratégias politicas: chimpanzé, Maquiavel e Gandhi. São Paulo: Edições Fundap, 1996.

MITRE, Sandra M. et al. Metodologias ativas de ensino-aprendizagem na formação profissional em saúde: debates atuais. Ciência \& Saúde Coletiva, Rio de Janeiro, v. 13, supl. 2, p. 2.133-2.144, 2008.

MOTTA, José I. J.; BUSS, Paulo; NUNES, Tânia C. M. Novos desafios educacionais para a formação de recursos humanos em saúde. Olho Mágico, Londrina, v. 8, n. 3, p.4-8, 2001. 
NUNES, Tânia C. M. Educação continuada: uma proposta para a área de epidemiologia no Sistema Único de Saúde no Brasil. Informe Epidemiológico do SUS, Brasília, ano II, n. 2, p.45-54, mar./abr. 1993.

NUNES, Tânia C. M.; FAGUNDES, Terezinha L. Q.; SOARES, Catharina L. M. Os cursos lato sensu na formação em saúde coletiva: evolução histórica e desafios contemporâneos. In: LIMA, Nísia T.; SANTANA, José P.; PAIVA, Carlos H. A. (orgs.). Saúde coletiva: a Abrasco em 35 anos de história. Rio de Janeiro: Editora Fiocruz, 2015. p. 151-167.

PAIM, Jairnilson S. Recursos humanos em saúde no Brasil: problemas crônicos e desafios agudos. São Paulo: Faculdade de Saúde Pública/USP, 1994.

PAIM, Jairnilson S. Reforma Sanitária Brasileira: contribuição para a compreensão e crítica. Salvador: EdUFBA; Rio de Janeiro: Fiocruz, 2008.

PAIM, Jairnilson S.; NUNES, Tânia C. M. Contribuições para um programa de educação continuada em saúde pública. Cadernos de Saúde Pública, Rio de Janeiro, v. 8, n. 3, p. 262-269, jul./set. 1992.

PASSERON, Jean-Claude. A reprodução: elementos para uma teoria do sistema do ensino. Petrópolis: Vozes, 2009.

PINTO, Isabela C. M. et al. Trabalho e educação em saúde no Brasil: tendências da produção científica entre 1990-2010. Ciência \& Saúde Coletiva, Rio de Janeiro, v. 18, n. 6, p. 15251534, Jun. 2013. Disponível em: <http:// www.scielo.br/scielo.php?script=sci_arttext\&pi$\mathrm{d}=$ S1413=81232013000600002-\&lng=en\&nrmiso >. Acesso em: 24 Set. 2019. http://dx.doi. org/10.1590/S1413-81232013000600002

RIBEIRO, Eliana C. O.; MOTTA, José I. J. Educação permanente como estratégia na reorganização dos serviços de saúde. Divulgação em Saúde para Debate, Rio de Janeiro, v. 12, p. 39-44, jul. 1996.

RICAS, Janete. A deficiência e a necessidade: um estudo sobre a formação continuada de pediatras em Minas Gerais. 232f. Tese (Doutorado) - Faculdade de Medicina de Ribeirão Preto, Universidade de São Paulo, 1994.

RYAN, Robin J. From recurrent education to lifelong learning. In: INVITATIONAL SEMINAR ON THE DELORS REPORT. Learning: the treasure within. Adelaide: The Flinders University Institute of International Education, 1999.

SAVIANI, Dermeval. Escola e democracia. São Paulo: Cortez/Autores Associados, 1989.

SAVIANI, Dermeval. O trabalho como princípio educativo frente às novas tecnologias: novas tecnologias, trabalho e educação - um debate multidisciplinar. Petrópolis: Vozes, 1994. p. 147-164.

SIMIONATTO, Ivete. O social e o político no pensamento de Gramsci. In: AGGIO, Alberto. Gramsci: a vitalidade de um pensamento. São Paulo: Ed. Unesp, 1998, p. 37-64.

SILVA, Jaqueline A. M.; PEDUZZI, Marina. Educação no trabalho na atenção primária à saúde: interfaces entre a educação permanente em saúde e o agir comunicativo. Saúde e Sociedade, São Paulo, v. 20, n. 4, p. 1.018-1.032, dez. 2011.

SILVA, Luiz A. A.; SODER, Rafael M.; PETRY, Letícia; OLIVEIRA, Isabel C. Educação permanente em saúde na atenção básica: percepção dos gestores municipais de saúde. Revista Gaúcha de Enfermagem, vol.38, n.1, e58779. Epub May 04, 2017. Disponível em: <http:// dx.doi.org/10.1590/1983-1447.2017.01.58779> Acesso em: 25 set. 2019.

SOUZA, Rosa P. S.; COSTA, Patrícia P. Educação permanente em saúde: experiência viva na Rede Brasileira de Escolas de Saúde Pública. Rio de Janeiro: Escola Nacional de Saúde Pública Sergio Arouca, 2016.

STAHLSCHMIDT, Ana P. M. Integralidade, construção e socialização de conhecimentos no contexto da educação permanente e atuação de profissionais da área da saúde. Interface: Comunicação, Saúde, Educação, Botucatu, v. 16 , n. 42 , p. 819-827, set. 2012. 
TESTA, Mario. Pensar em saúde. Porto Alegre: Artes Médicas/Abrasco, 1992.

TESTA, Mario. Análisis de instituciones hipercomplejas. In: MERHY, Emerson E.; ONOCKO-CAMPOS, Rosana (orgs.). Agir em saúde: um desafio para o público. São Paulo: Hucitec; Buenos Aires: Lugar Editorial, 1997. p. 17-70.
TESTA, Mario. Decidir en salud: ¿Quién? ¿Cómo? y ¿Por qué? Salud Colectiva, Buenos Aires, v. 3, n. 3, p. 247-257, 2007.

VASCONCELOS, Eymard M. Educação popular nos serviços de saúde. 3. ed. São Paulo: Hucitec, 1997. 